\title{
Inverse relation between Braak stage and cerebrovascular pathology in Alzheimer predominant dementia
}

\author{
Jonathan M R Goulding, David F Signorini, Sanjukta Chatterjee, James A R Nicoll,
} Janice Stewart, Robert Morris, G Alistair Lammie

Department of

Pathology

J M R Goulding

S Chatterjee

R Morris

G A Lammie

Department of Clinical Neurosciences, Edinburgh University, Western General Hospital , Edinburgh, UK

D Signorini

Department of Neuropathology, Southern General Hospital, Glasgow, UK J Nicoll

J Stewart

Correspondence to : Dr GA Lammie, Neuropathology

Laboratory, Alexander

Donald Building, Western

General Hospital, Crewe

Road, Ediburgh, UK, EH4

2XU. Fax 0044131537

1013; email

al@skull.dcn.ed.ac.uk

Received 2 December 1998 and in revised form

30 April 1999

Accepted17 June 1999

\begin{abstract}
The most common neuropathological substrates of dementia are Alzheimer's disease, cerebrovascular disease, and dementia with Lewy bodies. A preliminary, retrospective postmortem analysis was performed of the relative burden of each pathology in 25 patients with predominantly Alzheimer's disease-type dementia. Log linear modelling was used to assess the relations between ApoE genotype, Alzheimer's disease, and cerebrovascular disease pathology scores. Sixteen of 18 cases $(89 \%)$ with a Braak neuritic pathology score $\leqslant 4$ had, in addition, significant cerebrovascular disease, or dementia with Lewy bodies, or both. There was a significant inverse relation between cerebrovascular disease and Braak stage $(p=0.015)$. The frequency of the ApoE- 84 allele was $36.4 \%$. No evidence was found for an association between possession of the ApoE- $\& 4$ allele and any one pathological variable over another. In this series most brains from patients with dementia for which Alzheimer's disease is the predominant neuropathological substrate also harboured significant cerebrovascular disease or dementia with Lewy bodies. The data suggest that these diseases are perhaps pathogenetically distinct, yet conspire to produce the dementing phenotype.

(F Neurol Neurosurg Psychiatry 1999;67:654-657)
\end{abstract}

Keywords: Alzheimer's disease; cerebrovascular disease; dementia

Alzheimer's disease is the principal pathological substrate of clinical dementia, although other diseases may contribute to the phenotype, in particular cerebrovascular and Lewy body diseases. ${ }^{12}$ The relation between these diseases and their relative contributions to the dementing phenotype are poorly understood. ${ }^{13}$ A putative cerebrovascular component in Alzheimer's disease ${ }^{3}$ has been suggested to contribute to its pathogenesis. ${ }^{4}$ In this preliminary study, we staged Alzheimer's disease-type and cerebrovascular pathologies in a postmor- tem cohort of demented patients, to assess the relative burden of each. Further, we determined the relative strength of association of each with possession of the ApoE- $\varepsilon 4$ allele, to test the hypothesis that the association of ApoE- $\varepsilon 4$ with Alzheimer's disease represents, at least in part, its association with cerebrovascular disease.

\section{Methods}

Cases were selected from the 1994-7 Neuropathology files of the Western General Hospital, Edinburgh. All patients had a clinical diagnosis of sporadic senile dementia, the major neuropathological substrate of which was Alzheimer's disease, with or without Lewy bodies. Inpatient records, postmortem reports, and systemic and brain pathology were reviewed.

Standardised coronal, formalin fixed, paraffin embedded blocks were used for Braak staging of Alzheimer's disease lesions and cortical Lewy body screening - the blocks were frontal parasagittal including the cingulate gyrus, hippocampus, and mesial temporal neocortex at the level of the lateral geniculate nucleus, and occipital lobe at the level of the calcarine fissure including striate and parastriate cortices. Immunohistochemistry was performed on consecutive $5 \mu \mathrm{m}$ sections using monoclonal antibodies against the $\beta A 4$-amyloid (1:100; clone $6 \mathrm{~F} / 3 \mathrm{D}, \mathrm{DAKO})$ and tau proteins (1:3500; clone TAU-2, Sigma), and a polyclonal antibody against ubiquitin (1:300, DAKO).

Neuropathological indices were graded independently by two investigators, blind to the results for other indices and to ApoE genotype. Braak staging of neuritic pathology ${ }^{5}$ was modified for use with tau stained $5 \mu \mathrm{m}$ sections. ${ }^{6}$ Neurofibrillary tangles and neurophil threads density were assessed (absent,,,++++++ ) and cases assigned to one of Braak stages 3-6. Consecutive sections stained for $\beta$ A4-amyloid were used to derive an amyloid plaque stage. ${ }^{5}$

Cerebral amyloid angiopathy was scored using $\beta A 4$-amyloid stained sections of the frontal and occipital blocks. For leptomeningeal vessels, 100 vessels were counted in each section. Four categories of vessel involvement were defined: none, mild (slight, polar involve- 
ment), moderate (ring-like deposition, although not affecting full thickness of vessel wall) and severe (entire vessel wall affected). Each vessel was thus allocated $0,1,2$, or 3 points respectively, and the total calculated generating a single cerebral amyloid angiopathy grade: none $(0)=0$, mild $(1)=1-100$, moderate $(2)=101-200$, and severe $(3)=>200$. For cortical vessels, 10 random fields were studied at $\times 100$ magnification and the number of affected vessels counted to give a single grade: none $(\mathrm{O})=0$, mild $/$ moderate $(\mathrm{I})=1-25$ and severe $(\mathrm{II})=26$.

Haematoxylin and eosin stained stained sections of the substantia nigra and locus ceruleus were screened for brain stem Lewy bodies, and at least one cortical section stained for ubiquitin, including the cingulate gyrus, was screened for cortical Lewy bodies.

Haematoxylin and eosin and Luxol fast blue/cresyl violet stained sections from the same blocks were used to assess diffuse white matter disease. ${ }^{3}$ This was supplemented by examination of haematoxylin and eosin sections from more widely sampled brain regions (number of brain blocks/case: range 6-17; mean 11.2). Thus, four categories were derived: normal (0), mild (I), moderate (II), and severe (III) myelin loss. The number, size, and location of all focal infarcts was recorded, and the presence of any such lesion was used to generate an alternative upgraded cerebrovascular disease score.

ApoE genotyping was performed using a hot start polymerase chain reaction (PCR) method optimised for archival formalin fixed brain tissue. $^{7}$

Log linear modelling was used to assess the relations between a single cerebrovascular disease variable, a single Alzheimer's disease variable, and possession of the $\varepsilon 4$ allele (Splus for Windows V3.1, Statsci Europe, UK). The small sample size meant that some tables analysed were sparse, and $10^{-7}$ was added to all cells to ensure convergence. ${ }^{8}$ Sensitivity of the results to the size of this adjustment was

Neuropathology and ApoE genotype

\begin{tabular}{|c|c|c|c|c|c|c|c|c|c|c|c|}
\hline $\begin{array}{l}\text { Casel } \\
\text { age }(y) / \\
\text { sex }\end{array}$ & $\begin{array}{l}\text { Duration of } \\
\text { dementia } \\
(y)\end{array}$ & $\begin{array}{l}\text { Fixed } \\
\text { brain } \\
\text { weight } \\
(g)\end{array}$ & $\begin{array}{l}\text { Neuritic } \\
\text { pathology } \\
\text { stage }\end{array}$ & $\begin{array}{l}\text { Amyloid } \\
\text { plaque } \\
\text { stage }\end{array}$ & $\begin{array}{l}C A A s \\
l m\end{array}$ & $\begin{array}{l}\text { stage } \\
c\end{array}$ & $\begin{array}{l}\text { Lewy bodies } \\
\text { b/s cortical }\end{array}$ & $\begin{array}{l}\text { Diffuse white } \\
\text { matter } \\
\text { pathology stage }\end{array}$ & Focal infarcts & $\begin{array}{l}\text { Combined CVD } \\
\text { (focal and } \\
\text { diffuse) stage }\end{array}$ & $\begin{array}{l}\text { ApoE } \\
\text { genotype }\end{array}$ \\
\hline $1 / 80 / \mathrm{F}$ & 2 & 1270 & 6 & $\mathrm{C}$ & 1 & $\mathrm{O}$ & - & I & - & I & $2 / 4$ \\
\hline $2 / 85 / \mathrm{F}$ & 5 & 1275 & 3 & C & 2 & I & + & I & $\begin{array}{l}\text { Multiple, subacute, small infarcts in } \\
\text { R.MCA territory }\end{array}$ & II & $3 / 3$ \\
\hline 3/89/M & 5 & 1305 & 5 & $\mathrm{C}$ & 2 & I & - & II & - & II & $3 / 4$ \\
\hline $4 / 79 / \mathrm{F}$ & 4 & 1330 & 4 & $\mathrm{C}$ & 2 & I & - & II & $\begin{array}{l}1 \text { lacune in pons; } 1 \text { occipital cortical } \\
\text { micoinfarct }\end{array}$ & III & $3 / 4$ \\
\hline $5 / 86 / M$ & $1^{\star}$ & 1443 & $\leqslant 2$ & B & 0 & $\mathrm{O}$ & + & II & Small hippocampal CA1 infarct & III & $3 / 4$ \\
\hline 6/86/M & 2 & 1317 & 4 & B & 1 & I & - & I & - & I & $3 / 4$ \\
\hline 7/77/M & 7 & 1371 & 4 & $\mathrm{O}$ & 1 & I & - & II & - & II & $3 / 4$ \\
\hline 8/74/M & 3 & 1183 & 4 & $\mathrm{C}$ & 1 & $\mathrm{O}$ & - & II & - & II & - \\
\hline $9 / 82 / \mathrm{F}$ & NK & 1035 & 4 & C & 1 & I & - & I & - & I & $3 / 4$ \\
\hline $\begin{array}{l}10 / 75 / \\
\mathrm{F}\end{array}$ & NK & 1370 & 4 & $\mathrm{C}$ & 2 & I & + & I & 1 type $1 \mathrm{~b}$ lacune in putamen & II & $3 / 4$ \\
\hline $\begin{array}{l}11 / 90 / \\
\mathrm{F}\end{array}$ & NK & 1239 & 4 & C & 1 & $\mathrm{O}$ & - & I & $\begin{array}{l}\text { Putamen:one type 1a lacune and } \\
\text { type } 1 \mathrm{~b} \text { lacunes }\end{array}$ & II & - \\
\hline $\begin{array}{c}12 / 63 / \\
M\end{array}$ & 5 & 1359 & 6 & $\mathrm{C}$ & 1 & I & + & I & - & I & $3 / 3$ \\
\hline $\begin{array}{c}13 / 83 / \\
M\end{array}$ & 1 & 1331 & 4 & C & 3 & II & - & II & $\begin{array}{l}\text { Occasional cortical micro infarcts; } \\
\text { 1lacune in putamen and } 1 \text { in } \\
\text { thalamus }\end{array}$ & III & $3 / 4$ \\
\hline $\begin{array}{l}14 / 95 / \\
\mathrm{F}\end{array}$ & 1 & 1205 & 3 & $\mathrm{C}$ & 1 & I & - & III & - & III & $3 / 4$ \\
\hline $\begin{array}{l}15 / 80 / \\
M\end{array}$ & 1.5 & 1471 & 5 & C & 3 & II & - & II & - & II & $3 / 3$ \\
\hline $\begin{array}{l}16 / 82 / \\
\mathrm{F}\end{array}$ & 1.5 & 1254 & 4 & C & 1 & I & - & I & $\begin{array}{l}\text { Small cerebellar border zone infarcts } \\
\text { (recent); frontal subcortical lesion }\end{array}$ & II & $3 / 4$ \\
\hline $\begin{array}{c}17 / 67 / \\
M\end{array}$ & 14 & 1004 & 6 & B & 1 & I & - & I & - & I & $3 / 3$ \\
\hline $\begin{array}{c}\text { Casel } \\
\text { age } \\
(y) ! \\
\text { sex }\end{array}$ & $\begin{array}{l}\text { Duration of } \\
\text { dementia } \\
(y)\end{array}$ & $\begin{array}{l}\text { Fixed } \\
\text { brain } \\
\text { weight } \\
(g)\end{array}$ & $\begin{array}{l}\text { Neuritic } \\
\text { pathology } \\
\text { stage }\end{array}$ & $\begin{array}{l}\text { Amyloid } \\
\text { plaque } \\
\text { stage }\end{array}$ & $\begin{array}{l}C A A s \\
1 / m\end{array}$ & $\begin{array}{l}\text { stage } \\
c\end{array}$ & $\begin{array}{l}\text { Lewwy bodies } \\
\text { b/s cortical }\end{array}$ & $\begin{array}{l}\text { Diffuse white } \\
\text { matter } \\
\text { pathology stage }\end{array}$ & Focal hypoxic-ischaemic lesions & $\begin{array}{l}\text { Combined CVD } \\
\text { (focal and } \\
\text { diffuse) stage }\end{array}$ & $\begin{array}{l}\text { ApoE } \\
\text { genotype }\end{array}$ \\
\hline $\begin{array}{l}18 / 78 / \\
M\end{array}$ & $2^{\star}$ & 1560 & $\leqslant 2$ & B & 3 & I & + & I & 1 frontal cortical microinfarct & II & $3 / 3$ \\
\hline $\begin{array}{l}19 / 92 / \\
\mathrm{F}\end{array}$ & $\begin{array}{l}\text { Long } \\
\text { standing }\end{array}$ & 1098 & 4 & $\mathrm{C}$ & 3 & II & - & II & Several type $1 \mathrm{~b}$ lacunes in putamen & III & $4 / 4$ \\
\hline $\begin{array}{l}20 / 84 / \\
\mathrm{F}\end{array}$ & 6 & 1232 & 4 & $\mathrm{C}$ & 1 & $\mathrm{O}$ & + & II & - & II & $3 / 3$ \\
\hline$\stackrel{21 / 81 /}{M}$ & 7 & 1301 & 5 & $\mathrm{C}$ & 1 & I & - & I & - & I & - \\
\hline $\begin{array}{c}22 / 80 / \\
M\end{array}$ & 1 & 1270 & 3 & B & 1 & II & + & I & - & I & $3 / 4$ \\
\hline $\begin{array}{l}23 / 82 / \\
\mathrm{F}\end{array}$ & 2 & 1102 & 4 & $\mathrm{C}$ & 0 & $\mathrm{O}$ & - & I & $\begin{array}{l}\text { Type } 1 \mathrm{~b} \text { lacunes in thalamus; acute } \\
\text { bg infarct }\end{array}$ & II & $3 / 3$ \\
\hline $\begin{array}{l}24 / 77 / \\
\mathrm{F}\end{array}$ & $\begin{array}{l}\text { Long } \\
\text { standing }\end{array}$ & 1137 & 3 & B & 2 & I & + & II & 1 type $1 \mathrm{~b}$ lacune in putamen. & III & $4 / 4$ \\
\hline $\begin{array}{c}25 / 71 / \\
M\end{array}$ & 4 & 1574 & 5 & B & 2 & I & - & II & $\begin{array}{l}\text { Multiple cortical microinfarcts; type } \\
\text { 1b lacunes in thalamus and } \\
\text { putamen; type 1a lacunes in } \\
\text { putamen and pons }\end{array}$ & III & $3 / 3$ \\
\hline
\end{tabular}

ApoE = apolipoprotein $\mathrm{E} ; \mathrm{bg}=$ basal ganglia; $\mathrm{b} / \mathrm{s}=$ brain stem; $\mathrm{c}=$ cortical vessels; $\mathrm{CAA}=$ cerebral amyloid angiopathy; $\mathrm{CVD}=$ cerebrovascular disease; $\mathrm{L}=$ left; $1 \mathrm{~m}=$ leptomeningeal vessels; $\mathrm{MCA}=$ middle cerebral artery; $\mathrm{NK}=$ not known; $\mathrm{R}=$ right; $+/==$ present/absent. 
performed, with no qualitative change in the result. For the purposes of analysis, neuritic pathology stages 1-4 were grouped together and diffuse white matter disease stages II and III merged. The leptomeningeal cerebral amyloid angiopathy score was converted into "low" (none or mild) and "high" (moderate or severe) groupings. $p$ Values $\leqslant 0.05$ were considered significant.

\section{Results}

Relevant clinical and pathological details are shown in the table. In only one of the 25 cases (case 20) was the possibility of subcortical or multi-infarct dementia considered clinically; in the remainder the cause of dementia was either not specified or considered most likely to be Alzheimer's disease. In no case was there a history or clinical signs of stroke.

Twenty of 25 cases ( $80 \%$ ) had, in addition to varying degrees of Alzheimer's disease pathology, either significant cerebrovascular disease (18 cases), or Lewy bodies (eight cases), or both (six cases). Thus, only five cases $(20 \%)$ were "pure" Alzheimer's disease. Sixteen cases were placed in the "limbic" category (Braak stages 3 and 4) and seven in the "isocortical" category (stages 5 and 6). The two cases (5 and 18) with insufficient neuritic pathology for limbic stage disease were classified as Braak stage $\leqslant 2$. Only one case (7) was devoid of extracellular amyloid, and the remainder had a Braak amyloid plaque score of either $B(n=7)$ or $C$ $(\mathrm{n}=17)$.

Brain stem Lewy bodies were present in eight of 25 cases $(32 \%)$, in seven of which cortical Lewy bodies were also detected.

All cases showed some centrum ovale white matter pallor, relative to preserved subcortical $U$ fibres. In each there was a comparable loss of axons, hyaline arteriolosclerosis, and a few scattered macrophages and reactive astrocytes. In 13 cases $(52 \%)$ this diffuse white matter disease was considered within normal limits for age. Of the remainder, white matter disease was of moderate severity in 11 cases, and severe in one case. In four of the 12 cases with significant diffuse white matter disease, this was not documented in the original neuropathology report; in the remaining eight cases it was originally considered to be of no or minimal clinical significance. In 12 of 25 cases (48\%) there were small, focal infarcts. There were no large regional infarcts or haemorrhages, and no other significant neuropathology.

ApoE genotype was determined in 22 cases. Of these, $14(64 \%)$ possessed one or more $\varepsilon 4$ alleles. The individual allele frequencies were: $\varepsilon 2(2.3 \%), \varepsilon 3(61.3 \%)$, and $\varepsilon 4(36.4 \%)$.

Sixteen of 18 cases ( $89 \%)$ with a Braak neuritic pathology score of 4 had either significant cerebrovascular disease (a combined score of II or III), or Lewy bodies, or both. All six cases with a Braak neuritic pathology score of $\leqslant 3$ had such additional pathology. There was a significant inverse relation between cerebrovascular disease stage, both diffuse $(p=0.015)$ and combined diffuse/focal $(p=0.033)$, and Braak neuritic stage. In other words, as the severity of cerebrovascular disease increased, the Braak stage decreased. After controlling for this association, no evidence for significant associations between possession of $\varepsilon 4$ and either Alzheimer's disease (neuritic or amyloid plaque stages) or cerebrovascular disease stage was found. Combined cerebrovascular disease stage did correlate positively with leptomeningeal CAA severity $(p=0.008)$, but there was no evidence that either was associated with $\varepsilon 4$.

\section{Discussion}

Alzheimer, cerebrovascular, and Lewy body pathologies often coexist, ${ }^{129}$ yet the burden of each needed to cause dementia is unknown, as are their relative contributions in "mixed" cases. The presence of diffuse white matter disease in Alzheimer's disease brains is well documented, ${ }^{310}$ and is usually interpreted as being ischaemic. ${ }^{3}$ Focal infarcts may also affect the rate of cognitive decline in Alzheimer's disease. ${ }^{1112}$

Of 25 cases with Alzheimer predominant dementia, $18(72 \%)$ had a Braak neuritic pathology stage of 4 , corresponding at most to "clinically incipient" Alzheimer's disease. ${ }^{5}$ Of these 18 cases, 16 (89\%) also had either significant cerebrovascular disease, or Lewy bodies, or both. The inverse relation between cerebrovascular disease stage and neuritic pathology stage would seem to support the concept of synergistic pathologies. In other words, limbic stage Alzheimer's disease tends to manifest clinically if there is significant additional vascular pathology, analagous to a putative "unmasking" of early stage Alzheimer's disease by Lewy body pathology. ${ }^{13}$

The high frequency of "mixed pathology" in this series may relate to the selection criteria, and to the relatively high mean age of patients. However, our relatively limited screen for cortical Lewy bodies compared with consensus guidelines ${ }^{14}$ may have led to our underestimating the frequency of dementia with Lewy bodies. Notwithstanding, it seems clear that various pathologies conspire with Alzheimer's disease to produce the dementing phenotype.

Although our data do justify larger scale, prospective clinicopathological case-control studies, the small sample size in this preliminary survey, the range of disease durations and ages of disease onset, and the fact that the severity of cognitive deficit was not defined mean that they should not be overinterpreted. Although a standardised clinical diagnosis and a CERAD neuropathology diagnosis of Alzheimer's disease were not required, there is some evidence that this cohort is similar to many published Alzheimer's disease cohorts. Firstly, the $\varepsilon 4$ frequency in this series $(36.4 \%)$ closely approximated to that established by meta-analysis in late onset sporadic Alzheimer's disease (36.7\%). ${ }^{15}$ Secondly, recent studies of cases fulfilling (modified) CERAD criteria for Alzheimer's disease show that in a similar proportion there is neuropathological evidence of the same additional pathologies. ${ }^{1}$

The association of ApoE- $\varepsilon 4$ with late onset Alzheimer's disease is well documented. ${ }^{16-18} \mathrm{An}$ increased frequency of the ApoE- $\varepsilon 4$ allele has 
also been reported in coronary heart disease, atherosclerosis, ${ }^{19}$ and ischaemic cerebrovascular disease. $^{20}$ Perhaps the association of ApoE- $\varepsilon 4$ with late onset Alzheimer's disease may reflect, at least partly, an association with an underdiagnosed cerebrovascular component. Recent clinical studies of Alzheimer's disease cohorts have linked ApoE- $\varepsilon 4$ with atherosclerosis, ${ }^{21} 22$ and with white matter lesions, ${ }^{23}$ and with focal cerebrovascular lesions in postmortem studies. ${ }^{24}$ Although our data did not show which of the various brain pathologies was being "driven" by the $\varepsilon 4$ allele they do illustrate how such an approach may be of value in larger scale studies.

The diffuse white matter disease in Alzheimer's disease, presumed to be ischaemic, ${ }^{3}$ could be mediated by a variety of cardiac, large vessel atheromatous or small vessel pathologies, either separately or in combination, some but not all of which may be associated with possession of ApoE- $\varepsilon 4$. This study establishes a need for larger surveys to show the clinically significant cause and effect relations, and we describe a potentially useful approach. We emphasise the importance of screening for additional pathology and incorporating it into the more objective category of "Alzheimer predominant dementia". We describe an inverse relation between cerebrovascular disease and Alzheimer's disease which requires confirmation.

We are grateful to Angela Penman for her secretarial assistance, and to Drs Jeanne Bell, Stephen Wharton, and James Ironside for their comments on the manuscript.

1 Nagy Z, Esiri MM, Jobst KA, et al. The effects of additional pathology on the cognitive deficit in Alzheimer disease. $f$ Neuropathol Exp Neurol 1997;56:165-70.

2 Holmes C, Cairns N, Lantos P, et al. Validity of the current clinical criteria for Alzheimer,s disease, vascular dementia and dementia with Lewy bodies. Br $\mathcal{F}$ Psychiatry 1999;174 $45-50$.

3 Brun A, Englund E. A white matter disorder in dementia of the Alzheimer type: a pathoanatomical study. Ann Neurol 1986;19:253-62.

4 Gold G, Giannakopoulos P, Bouras C. Reevaluating the role of vascular changes in the differential diagnosis of Alzheimer's disease and vascular dementia. European Neurology 1998;40:121-9.

5 Braak H, Braak E. Neuropathological staging of Alzheimerrelated changes. Acta Neuropathol 1991;82:239-59.
6 Gertz H-J, Xuereb J, Huppert F, et al. Examination of the hierarchical model of neuropathological staging in normal aging a

7 Nicoll JAR, Burnett C, Love S, et al. High frequency of apolipoprotein $\mathrm{E} \varepsilon 2$ allele in hemorrhage due to cerebral amyloid angiopathy. Ann Neurol 1997;41:716-21.

8 Agresti A. An introduction to categorical data analysis. New York: Wiley, 1996:190-2.

9 Bowler JV, Munoz DG, Merskey H, et al. Fallacies in the pathological confirmation of the diagnosis of Alzheimer's disease. I Neurol Neurosurg Psychiatry 1998;64:18-24.

10 Rezek DL, Morris JC, Fulling KH, et al. Periventricular white matter lucencies in senile dementia of Alzheimer type and in normal aging. Neurology 1987;37:1365-8.

11 Snowdon DA, Greiner LH, Mortimer JA, et al. Brain infarction and the clinical expression of Alzheimer disease. The Nun study. FAMA 1997;277:813-17.

12 Heyman A, Fillenbaum GG, Welsh-Bohmer KA, et al. Cerebral infarcts in patients with autopsy-proven Alzheimer's disease. CERAD, part XVIII. Neurology 1998;51:159-62.

13 Brown DF, Dababo MA, Bigio EH, et al. Neuropathologic evidence that the Lewy body variant of Alzheimer disease represents coexistence of Alzheimer disease and idiopathic Parkinson disease. $\mathcal{F}$ Neuropathol Exp Neurol 1998;57:3946.

14 McKeith IG, Galasko D, Kosaka K, et al. Consensus guidelines for the clinical and pathological diagnosis of dementia with Lewy bodies (DLB): report of the consortium on dementia with Lewy bodies international workshop. Neurology 1996;47:1113-24.

15 Farrer LA, Cupples LA, Haines JL, et al. Effects of age, sex, and ethnicity on the association between apolipoprotein $\mathrm{E}$ genotype and Alzheimer disease. A meta-analysis. $7 A M A$ 1997;278:1349-56.

16 Saunders AM, Strittmatter WI, Schmechel D, et al. Association of apolipoprotein E allele $\varepsilon 4$ with late-onset familial and sporadic Alzheimer's disease. Neurology 1993;43: 1467-72

17 Poirier J, Davignon J, Bouthillier D, et al. Apolipoprotein E polymorphism and Alzheimer's disease. Lancet 1993;342: 697-9.

18 Strittmatter WI, Saunders AM, Schmechel D, et al. Apolipoprotein E: high-avidity binding to $\beta$-amyloid and increased frequency of type 4 allele in late-onset familial Alzheimer disease. Proc Natl Acad Sci USA 1993;90:197781 .

19 Davignon J, Gregg RE, Sing CF. Apolipoprotein E polymorphism and atherosclerosis. Arteriosclerosis 1988;8: $1-21$.

20 Pedro-Botet J, Senti M, Nogues X, et al. Lipoprotein and apolipoprotein profile in men with ischaemic stroke. Role of lipoprotein (a), triglyceride-rich lipoproteins, and apolipoprotein E polymorphism. Stroke 1992;23:1556-62.

21 Kosunen O, Talasniemi S, Lehtovirta $\mathrm{M}$, et al. Relation of coronary atherosclerosis and apolipoprotein E genotypes in coronary atherosclerosis and apolipoprotei

22 Hofman A, Ott A, Breteler MMB, et al. Atherosclerosis, apolipoprotein E, and prevalence of dementia and Alzheimer's disease in the Rotterdam study. Lancet 1997;349:151-4

23 Skoog I, Hesse C, Aevarsson O, et al. A population study of apoE genotype at the age of 85: relation to dementia, cerebrovascular disease, and mortality. 7 Neurol Neurosurg Psychiatry 1998;64:37-43.

24 Kalaria RN, Cohen DL, Premkumar DRD. Apolipoprotein $\mathrm{e}$ alleles and brain vascular pathology in Alzheimer's disease. Ann NY Acad Sci 1996;777:266-70. 